\title{
SERVIÇO SOCIAL EM PORTUGAL: PERCURSO CRUZADO ENTRE A ASSISTÊNCIA E OS DIREITOS
}

Maria Irene Lopes Bogalho de Carvalho ${ }^{l}$

\section{RESUMO}

Este ensaio analisa o desenvolvimento da formação e da profissão do Serviço Social em Portugal a partir de tempos e espaços determinados. Para o efetuar realizamos uma pesquisa bibliográfica centrada em textos de referência, publicados nestes últimos anos e também na experiência da autora enquanto docente no Sistema de Ensino Superior em Portugal. Situamos a emergência, a construção e os desenvolvimentos recentes nas duas dimensões em estudo, a formação e a profisssão e refletimos sobre os desafios na atualidade. Consideramos que, quer a formação quer a profissão do Serviço Social sofreram mudanças substantivas desde o seu surgimento até à atualidade, decorrente das transformações sociais associadas à mudança do sistema político, da evolução do conhecimento das Ciências Sociais e Humanas e da complexidade dos problemas sociais constituindo-se enquanto percurso cruzado entre a assistência e os direitos.

PALAVRAS-CHAVE: Serviço Social, Formação, Profissão, Assistência, Direitos

\section{INTRODUÇÃO}

Uma análise cuidada ao desenvolvimento e evolução do Serviço Social em Portugal permite conferir que apesar dos constrangimentos políticos este soube, sobretudo nos últimos quarenta anos, ainda que de forma implícita, distanciar-se de uma posição de controlo social associada à repressão e à caridade e integrar teorias, métodos, técnicas e princípios e valores associados aos direitos humanos.

\footnotetext{
1 Ph.D em Serviço Social, docente universitária e investigadora, Lisboa, Portugal. E-mail: mariacarvalho21@hotmail.com.

Revista Serviço Social \& Saúde. UNICAMP Campinas, v. IX, n. 10, Dez. 2010
} 
Este ensaio analisa o desenvolvimento da formação e da profissão do Serviço Social em Portugal a partir de tempos e espaços determinados. O primeiro refere-se à institucionalização da formação e da profissão e desenvolveu-se entre a década de trinta e quarenta do século vinte. O segundo centra-se no período da década de cinquenta, sessenta e meados da década de setenta e refere-se às mudanças sociais e descontinuidades profissionais operadas nesse âmbito. $\mathrm{O}$ terceiro reporta-se à reafirmação da profissão revelando as suas continuidades e mudanças no período que vai desde a Revolução de Abril de 1974, início da democracia, até à década de noventa. O quarto período situa-se entre a década de noventa até 2004 onde assistimos à consolidação da profissão. Por último o período da reforma do ensino de acordo com as regras e normas de Bolonha, num contexto de crise financeira global.

Para realizar o ensaio optamos por uma pesquisa essencialmente bibliográfica centrada em textos de referência, publicados nestes últimos anos e também na experiência da autora enquanto docente no Sistema de Ensino Superior em Portugal. Consideramos que, quer a formação quer a profissão do Serviço Social sofreram mudanças substantivas desde o seu surgimento até à atualidade, decorrente das transformações sociais associadas à mudança do sistema político, da evolução do conhecimento das ciências sociais e humanas e da complexidade dos problemas sociais constituindo-se enquanto percurso cruzado entre a assistência e os direitos. Vejamos de seguida esse desenvolvimento e transformação. 


\section{1 - INSTITUCIONALIZAÇÃO DA FORMAÇÃO E DA PROFISSÃO}

A formação, do Serviço Social em Portugal, foi institucionalizada com a criação de três escolas de Serviço Social na década de trinta a quarenta do século XX. Estas surgiram enquadradas no projeto político e ideológico do Estado Novo e eram da responsabilidade de organizações privadas religiosas e ou de carácter coletivo/corporativo ${ }^{2}$. Em 1939 foi reconhecido o diploma desta "nova profissão" (MARQUES; MOURO, 2004, p. 182).

A emergência do Serviço Social em Portugal decorre do movimento europeu de construção e institucionalização do Serviço Social como uma forma de ação e controle sobre os "pobres". O Serviço Social em Portugal adquiriu uma peculiar especificidade, face a países europeus do centro e norte da Europa pois foi instituído a partir de um "projeto ditatorial” (MARQUES; MOURO, 2004, p. 182) de educação moral nacional associado ao autoritarismo corporativista (cf. MARTINS, 1993) desenvolvido por entidades privadas de âmbito religioso e não num contexto de democratização da vida pública e da concretização de direitos, civis, políticos e sociais. O projeto político português não integrava esses direitos, pelo contrário reproduzia as desigualdades sociais sob a ideologia de "apuramento da raça" (MARQUES; MOURO, 2004, p. 182).

A institucionalização da formação e da profissão teve início na década de trinta do século vinte com a abertura da primeira escola de Serviço Social ${ }^{3}$ e uma segunda em Coimbra ${ }^{4} 1937$ - denominada Escola Normal e na década de cinquenta a

\footnotetext{
${ }^{2}$ As Escolas de Lisboa e Porto eram tuteladas pelo patriarcado e a de Coimbra pela Assembleia Municipal.

${ }^{3}$ Em 1935, abertura da primeira escola de Serviço Social em Lisboa: Instituto de Serviço Social gerido pelo Patriarcado.

${ }^{4}$ Esta escola era da responsabilidade da Assembleia Municipal.

Revista Serviço Social \& Saúde. UNICAMP Campinas, v. IX, n. 10, Dez. 2010
} 
Escola do Porto ${ }^{5}$. O surgimento da primeira escola de Serviço Social está associado ao congresso da União Nacional onde foi debatido o projeto político ideológico do denominado Estado Novo ${ }^{6}$. Este projeto considerava que as instituições de caridade deveriam cuidar da assistência social organizada e exigia a criação de escolas e de profissionais habilitados para o seu exercício ${ }^{7}$.

Para concretizar este projeto vieram expressamente de França assistentes sociais para estabelecer e organizar a formação. O modelo "teórico" assentava em bases positivistas consubstanciadas na doutrina social da Igreja e na Ciência Social ${ }^{8}$ de Le Play (MARTINS, 1993, p. 10). O Serviço Social tornou-se um instrumento de concretização das ideias reformistas implícitas nestas duas perspectivas teóricas e filosóficas e nas do projeto político de Educação Nacional - Deus, pátria e família.

O curso de Serviço Social era organizado em três anos. A formação curricular incluía três grandes temas: Educação Social; Medicina Social e o exercício da prática em instituições sociais. O curso versava sobre o Serviço Social e os seus modos de funcionamento, enfatizando a dimensão individual e familiar assim como as práticas, implicando a realização de inquéritos, visitas, relatórios e monografias (cf. MARTINS, 1993). As instituições existentes neste contexto sociohistórico eram asilos e albergues, reformatórios, tutorias de menores, hospitais e instituições sociais associadas à religião

\footnotetext{
${ }^{5}$ Organizada pela Associação de Cultura e Serviço Social da Diocese do Porto.

${ }^{6}$ Neste congresso foi defendida a criação de escolas de Serviço Social pela Condessa de Rilvas. Nesta década surgiram algumas medidas sociais ligadas a esse projeto. São disso exemplo, a lei da repressão da mendicidade de 1931 cujo responsável era o Ministério da Administração Interna; a Lei da Previdência Social em 1935. Esta seguia as instruções estabelecidas no Estatuto Nacional do Trabalho competindo aos organismos corporativos a criação de diferentes instituições de previdência. Esta protegia os trabalhadores dos setores do comércio, indústria e serviços do Estado associados a organismos corporativos. E a lei da assistência regulamentada em 1944 que remetia para as instituições religiosas a assistência moral e religiosas aos indivíduos.

${ }^{7}$ Estas escolas de carácter particular eram as únicas responsáveis pela formação de assistentes sociais no nosso país até ao final do século XX.

${ }^{8}$ Este autor estudou o modo de vida dos operários europeus, preconizando a defesa da família tradicional camponesa, alargada de herdeiro único, cuja responsabilidade era a de organizar a ordem familiar.
}

Revista Serviço Social \& Saúde. UNICAMP Campinas, v. IX, n. 10, Dez. 2010 
como as Santas Casas da Misericórdia ${ }^{9}$. Além de assistentes sociais formavam-se também nessas escolas visitadoras escolares com curso, de menor duração, de três meses.

Além destas características o Serviço Social era essencialmente e "obrigatoriamente" feminino dirigindo-se a mulheres das classes burguesas (cf. GARNIER, 1999). Estas, segundo o autor (op. cit.) tinham de ter um perfil vocacional e padrões morais associados à ideologia do Estado Novo. A profissão estava associada às elites "femininas" mas integrava-se num quadro de desigualdade de direitos entre homens e mulheres. Numa sociedade patriarcal, estas só poderiam exercer uma profissão enquanto solteiras e no caso das casadas com consentimento do marido. Por exemplo a primeira assistente social a exercer a profissão na Misericórdia de Lisboa foi admitida em 1944 e na década seguinte até 1958 foram admitidas mais quatro (FERNANDES et. al., 1993, p. 41).

A escassez de profissionais no ativo nesse período pode ser também imputada ao "cariz voluntário da ação profissional” (FERNANDES et. al., 1993, p. 41). Esta era exercida por pessoas sem formação profissional decorrente do número relativamente reduzido de profissionais que era formada nas escolas e que estava disponível para exercer a profissão ${ }^{10}$. Neste período a ação social desenvolvida por assistentes sociais, visitadores e ou voluntárias confundia-se com a ação religiosa e de educação moral nacional. Apesar de em 1950 ter sido organizado o Sindicato de Assistentes Sociais, educadoras familiares e outros profissionais de Serviço Social (cf. MARTINS, 2003, p.

\footnotetext{
${ }^{9}$ Lembrar que a ação social das misericórdias era semelhante à ação religiosa. Lei da Assistência Decreto de Lei 35108 de 7 de Novembro artigo 108 considera que "os estabelecimentos de assistência e beneficências têm como objectivo prestar assistência religiosa e moral aos assistidos, sobretudo as Irmandades da Misericórdia". Em 1963 esta lei foi reformulada - Lei 2120 De 19 de Julho - e imposto um sistema dual - a misericórdia como instituição de assistência e a misericórdia como instituição religiosa.

${ }^{10}$ Durante este período as mulheres casadas tinham de ter permissão do marido para exercer a profissão e aquelas que o faziam optavam por ser "donas de casa".
} 
52) os seus associados deveriam defender os interesses da nação, subordinando-os aos interesses pessoais e de classes.

\section{2 - MUDANÇAS SOCIAIS E DESCONTINUIDADES PROFISSIONAIS}

A construção do conhecimento em Serviço Social está associada ao contexto social onde o mesmo se desenvolve. A partir do final da década de cinquenta e sessenta surgem ideias contrárias ao conservadorismo e ao corporativismo de Estado, associadas a movimentos políticos contrários ao regime surgindo igualmente algumas cooperativas culturais (cf. MARTINS, 2003, p. 52). O regime político mostra, por um lado uma certa apetência para alterações na orientação da política social mas por outro, maior controlo social face a essas ideias e movimentos. Algumas destas ideias associadas aos direitos humanos foram defendidas por algumas assistentes sociais que as levaram à prisão e à tortura (cf. MARTINS, 2003, p. 52). Numa outra latitude estes movimentos foram reprimidos pela guerra colonial.

Durante a década de sessenta e princípio de setenta a intervenção do Estado situa-se sobretudo na melhoria das condições de saúde e de proteção social no sentido de "reprodução da força de trabalho" (MARQUES, MOURO, 2004, p. 183). Esta intervenção foi consubstanciada através da reformulação do Sistema de Previdência em articulação com a assistência ${ }^{11}$ e de processos de intervenção direcionados para o desenvolvimento das comunidades.

Neste contexto de mudanças políticas e sociais também no Serviço Social foram operadas transformações. A primeira foi o reconhecimento do curso de Serviço

\footnotetext{
${ }^{11}$ Lei 2115 de 15 de Junho de 1962, regulamentada pelo Decreto de Lei no 45266 de 23709 de 1963. Na prática esta lei terminou com a exclusividade de criação de instituições de Previdência por parte dos organismos corporativos, passando a ser criadas novas instituições de previdência por iniciativa do Estado. Por exemplo em 1965 foi criado o Centro Nacional de Pensões por ordem Ministerial no 21546 de 23 de Setembro.
} 
Social como ensino superior, mas não universitário, em 1961, por despacho ministerial. Foi também nesta década, em 1964, que os "rapazes" foram autorizados a frequentar o curso de Serviço Social (MARQUES, MOURO, 2004, p. 184).

Relativamente à formação, enquanto na Europa e Estados Unidos se exercitavam as metodologias de grupos e comunidade, métodos associados à psicanálise e psicodinâmicas, em Portugal continuava-se a exercitar-se o modelo de Medicina Social associado à mudança de comportamento individual dos pobres, o case work (cf. MARTINS, 2003, p. 53). Cientes destas inovações internacionais as escolas debatiam-se pela sua implementação nos curriculum. Contudo esta pretensão não foi aceite pelas entidades gestoras, continuando a linha condutora introduzida no início da constituição das escolas. O conhecimento das Ciências Sociais, introduzido, era filtrado pela doutrina católica e pelo Estado.

Na década de sessenta inicia-se um processo de desvinculação religiosa, ainda que sutil, passando as unidades curriculares de Doutrina Social da Igreja e de Orientação Religiosa a ser optativas (cf. MARTINS, 2003, p. 53). Para esta desvinculação contribuiu a vinda de assistentes sociais brasileiras para dar formação na escola de Lisboa. Estas introduziram mudanças substantivas na formação teórica e prática direcionada para a ressignificação do Serviço Social associado ao movimento de Reconcetualização e de consciencialização de Paulo Freire (cf. MARQUES, MOURO, 2004; FOOK, 2003).

O contexto de mudanças da realidade social e continuidades das orientações políticas e ideológicas traduziu-se numa consciencialização profissional da necessidade de mudar as orientações da profissão. As assistentes sociais, agora com mais expressão numérica, estavam integradas em empresas, instituições de caridade religiosas e serviços do Estado e começam a questionar as suas práticas (cf. MARTINS, 2003, p. 
54). Neste contexto o sindicato ${ }^{12}$ dos assistentes sociais torna-se um meio para melhorar as condições de trabalho e de obtenção de reconhecimento profissional, atuando no sentido de modificar a representação da profissão, de "missionária" para uma profissão qualificada e socialmente útil (cf. MARTINS, 2003, p. 55). Contudo só a partir de 1974 é possível "regenerar" a profissão. É neste período os assistentes sociais procuram construir uma imagem moderna da mesma, comprometida com a justiça social e o bemestar social.

\section{3 - REAFIRMAÇÃO DA PROFISSÃO: MUDANÇAS E CONTINUIDADES}

A fase da reafirmação da profissão dá-se entre 1974 e 1990. A partir de 1974 a profissão desenvolveu-se a par com a implementação dos regimes democráticos, a institucionalização das Ciências Sociais e com a assunção de responsabilidades sociais por parte do Estado. Esta mudança permitiu à profissão consolidar o seu estatuto profissional através da criação de associações profissionais, carreiras, definição de conteúdos funcionais, reconhecimento e valorização da formação académica permitindo igualmente a reconfiguração dos cursos de bacharelato para licenciatura em 1989 e outras formações pós-graduadas como mestrados ${ }^{13}$. O Serviço Social desenvolveu, consolidou e reafirmou o seu papel profissional na sociedade portuguesa contribuindo para a melhoria de condições de vida e de padrões de bem-estar.

Neste período, 1974-1990, a profissão "regenerou-se" tentando criar uma imagem moderna com intervenções inovadoras e alternativas (cf. MARQUES,

\footnotetext{
${ }^{12}$ Esta mudança na ação do sindicato só foi possível com a abertura sindical de 1969-1970 (cf. MARTINS, 2003, p. 55).

${ }^{13}$ Os primeiros mestrados e doutoramentos em Serviço Social surgiram na década de 90, a II edição iniciou-se em 1991, a partir de um protocolo com a Pontificia Universidade Católica de São Paulo Brasil e o Instituto de Serviço Social de Lisboa. Em 20/12/1993 foi apresentada pelo ISSS uma candidatura ao Ministério da Educação para a organização de mestrado. A Portaria $\mathrm{n}^{\circ}$ 182/95 de 6 de Maio autoriza o mestrado em Serviço Social ministrado pelo Instituto Superior de Serviço Social.

Revista Serviço Social \& Saúde. UNICAMP Campinas, v. IX, n. 10, Dez. 2010
} 
MOURO, 2004) associadas à promoção de responsabilidades do Estado pela área social. A ação dos profissionais alterou-se radicalmente integrando-se no contexto das políticas sociais setoriais: saúde, segurança social, justiça, habitação, trabalho e educação.

Foi também durante este período que os assistentes sociais se organizaram como classe. Em 1978 surgiu a Associação de Profisssionais de Serviço Social - APSS. Na década subsequente, esta associação, juntamente com as escolas, com especial destaque para a de Lisboa e do Porto iniciaram um período de luta, ação política, pelo reconhecimento do grau superior ao curso de Serviço Social e consequentemente à profissão. Para esse processo de mudança contribuiu o reconhecimento da licenciatura em $1989^{14}$ e a passagem dos anos de formação de quatro para cinco anos. A mesma incluía dois anos com uma base teórica com disciplinas nas áreas do Serviço Social, Sociologia, Psicologia do Comportamento pessoal e organizacional, Direito assim como Métodos e Técnicas da Investigação Científica.

Nos dois anos seguintes, para além desses conteúdos disciplinares, a formação integrava uma dimensão prática, os estágios, com o desenvolvimento de metodologias específicas do Serviço Social no contexto das políticas setoriais com seminários de acompanhamento. O último ano era dedicado exclusivamente ao processo de investigação científica o qual culminava com um trabalho de investigação. Esta transformação da formação permitiu construir um corpo profissional competente ao nível do saber, saber fazer, saber comunicar e do saber ser assistente social integrando vários campos, o da ação direta, o da concepção de políticas, da avaliação, da docência e da investigação.

\footnotetext{
${ }^{14}$ Portaria $n^{\circ} 793$ de 8 de Setembro de 1989, pelo Instituto de Lisboa e $n^{\circ} 797$ de 9 de Setembro de 1989 no Instituto do Porto.

Revista Serviço Social \& Saúde. UNICAMP Campinas, v. IX, n. 10, Dez. 2010
} 
Esta mudança potenciou o desenvolvimento de cursos de pós-graduação e especialização académica, mestrados e doutoramentos, estes últimos, em articulação com a Pontifícia Universidade Católica de São Paulo ${ }^{15}$. Esta alteração na formação configurou um corpo profissional especializado e altamente qualificado para a intervenção social em paridade com outras formações.

\section{4 - A CONSOLIDAÇÃO DA PROFISSÃO}

A partir da década de 1990 iniciou-se um processo de consolidação da profissão. A reconfiguração da formação académica está associada à reestruturação das políticas públicas no governo do então primeiro ministro socialista António Guterres. Este introduziu a ideia de políticas ativas, participadas pelos agentes intervenientes sejam utilizadores sejam prestadores dos suportes, permitindo o estabelecimento de um novo pacto social com as instituições particulares de solidariedades responsáveis pela ação social junto de crianças, jovens, pessoas idosas e outras áreas de intervenção social, culminado em 1996 com a criação do rendimento mínimo garantido em Portugal, atualmente denominado de rendimento social de inserção.

O programa assume que todos os indivíduos que não tivessem um rendimento inferior ao valor da pensão social poderiam candidatar-se e beneficiar de medidas de combate à pobreza e exclusão. Este princípio trouxe novos públicos para a profissão, associada ao trabalho com grupos desfavorecidos. Os assistentes sociais são agora confrontados com uma classe de "novos pobres", como as famílias monoparentais, as pessoas portadoras de HIV/SIDA e toxicodependentes, grupos étnicos, desempregados de longa duração, pessoas idosas dependentes, entre outros. Esta medida potenciou igualmente o surgimento de algumas novas respostas para este tipo de públicos, assim

\footnotetext{
${ }^{15}$ Organizado pelo Instituto Superior de Serviço Social de Lisboa.

Revista Serviço Social \& Saúde. UNICAMP Campinas, v. IX, n. 10, Dez. 2010
} 
como novas metodologias de intervenção, que se requeriam integradas e articuladas em rede.

Os assistentes sociais constituíram-se como os principais profissionais na concretização desta medida de política. Este programa aliado ao investimento do Estado em cuidados sociais na dependência permitiu dar uma visibilidade societal nunca antes vista na profissão. A nova configuração das políticas e responsabilidades do Estado e dos restantes agentes pela proteção social e criação de bem-estar ${ }^{16}$, favoreceu também o aumento da oferta formativa em Serviço Social. Agora entidades universitárias e institutos politécnicos públicos e privados oferecem formação ao nível das licenciaturas, mestrados e doutoramentos em Serviço Social.

O desenvolvimento da formação e da profissão do Serviço Social está associado à assunção das responsabilidades do Estado na formação dos assistentes sociais, num quadro de valorização e visibilidade das políticas sociais de combate à pobreza, e por uma crise na formação superior da área das Ciências Sociais e Humana, por exemplo associada a cursos tradicionais que tinham pouca procura por parte dos alunos. A formação e a profissão assumiram um carácter proativo e participado nas políticas de inclusão.

\footnotetext{
${ }^{16}$ Em Portugal e nos restantes países do sul da Europa estas responsabilidades são geralmente assumidas não só pelo Estado mas por outros atores envolvidos, como seja as organizações não lucrativas; a família e o mercado. Na criação de um bem-estar "familialista".

Revista Serviço Social \& Saúde. UNICAMP Campinas, v. IX, n. 10, Dez. 2010
} 


\section{5 - DESAFIOS À PROFISSÃo}

Em Portugal o "Serviço Social"17 está associado à profissão de assistente social $^{18}$. Esta denominação decorre do processo sociohistórico de implementação da formação do Serviço Social em Portugal. Desde 1974 que em Portugal se tem tentado contrariar a ideia "generalizada" de que o Serviço Social é um domínio essencialmente da "ação assistencialista" ou da intervenção social com indivíduos ou grupos, geralmente identificados, pela classe burguesa, com a "pobreza e exclusão social”. Esta linha de pensamento associa os problemas sociais ao próprio indivíduo e o Serviço Social é remetido para uma profissão conservadora que serve os interesses dos grupos dominantes, de controlo sobre os pobres, sendo por vezes "um joguete do poder", associado a um certo pragmatismo/imediatismo na resolução das questões, de uma forma rápida, sem refletir, "porque tem de ser feito assim", sem atender a que “implicações são que essas ações têm para a vida das pessoas” (cf. NEGREIROS, 1995; FOOK, 2003).

\footnotetext{
${ }^{17}$ Esta denominação decorre do processo de implementação da formação de Social Work em Portugal. As primeiras Escolas (em 1935, Lisboa, em 1937 em Coimbra e em 1957, no Porto) adotaram o Modelo de Formação Francês. Para a primeira escola vieram expressamente duas assistentes sociais desse país, implementar o modelo de intervenção social associado a Le Play e consubstanciado através do projeto político do denominado "Estado Novo". Este projeto político ditatorial corporativista e sectarista visava o apuramento de uma raça superior e a moralização dos pobres através da assistência social. Esta estava a cargo das organizações não lucrativas da Igreja Católica (Santas Casas das Misericórdias e paróquias) associada a práticas repressivas dos pobres ou "viciosos" como eram denominados nesse contexto político e social.

${ }^{18}$ A categoria profissional para efeitos de carreira na Administração Pública central e ou local é idêntica a outras licenciaturas e comporta as seguintes categorias, Técnico Superior de Serviço Social estagiário; técnico de $2^{\mathrm{a}}$ classe; de $1^{\circ}$ Classe; principal, assessor e assessor principal. O seu vencimento pode ir de 1250 euros a 3000 euros (valores de 2007). Contudo nas organizações não lucrativas a carreira rege-se por outro sistema e engloba técnicos de $2^{\mathrm{a}}$ classe, de $1^{\mathrm{a}}$ classe e Directores de Serviços e ou Coordenadores. O seu vencimento é inferior ao da Administração Central e a progressão na carreira é limitada e por vezes nestas instituições só existe um assistente social com as funções de Coordenador e ou Director de Serviços.
} 
A revolução democrática de 1974 permitiu contrariar a representação moralista da profissão, associada às políticas públicas de base democrática ${ }^{19}$. Neste âmbito integrou-se tanto no campo de análise e de ação interdisciplinar, entre o social, o político, o económico e o cultural, como no da ação reivindicativa dos profissionais face ao estatuto formativo e profissional. As escolas, o sindicato e a associação de profissionais lutavam por uma nova revalorização da profissão, incluindo o reconhecimento da formação como superior. Esta revalorização deu-se no final da década de oitenta com o reconhecimento da licenciatura em Serviço Social.

Neste contexto de mudança o Serviço Social ganhou um novo entendimento. Mais do que uma profissão que utiliza métodos e técnicas multidisciplinares, permitindo-lhe analisar a ação social e atuar sobre ela, modificando as condições de desigualdade, o Serviço Social assume-se hoje como uma disciplina científica de maior relevo na atualidade. Contudo o seu campo do conhecimento e de ação é construído na relação contraditória entre o "querer" (ação) e o "poder" (estrutura), entre o "necessário" (a demanda/necessidade) e o "possível" (norma), entre o básico e o mínimo (cf. ANDRADE, 2001). É nesta relação de desigualdade ${ }^{20}$ que o Serviço Social se move e se constrói efetivando direitos, justiça social, equidade e autodeterminação dos indivíduos, isto é, a concretização da cidadania.

É uma profissão essencialmente feminina e cerca de três mil são sócios da APSS. Estima-se, contudo que existam cerca de dez mil assistentes sociais em Portugal. A sua ação exerce-se na Administração Central (ministérios e institutos públicos) e local (câmaras municipais e juntas de freguesias) e em organizações não lucrativas e algumas

\footnotetext{
19 Primeira Constituição da República portuguesa foi rectificada em 1976, institui direitos cívicos, políticos e sociais iguais para homens e mulheres e se construiu uma sociedade democrática baseada nos direitos humanos. Foi também nesta década que em Portugal se institui universitário das Ciências Sociais como a Sociologia, Antropologia e a Psicologia.

${ }^{20}$ Portugal é um dos países da Europa com a maior taxa de pobreza cerca de $20 \%$ da população.
} 
lucrativas e empresas. $\mathrm{Na}$ administração central insere-se nas políticas setoriais nas áreas da segurança social (ação directa, rendimento social de inserção, programa de luta contra a pobreza, crianças em risco e perigo, idosos, deficientes, refugiados, toxicodependência, entre outros) sobretudo na concretização de suportes económicos e sociais; da saúde na área dos cuidados primários (equipas dos cuidados continuados a pessoas dependentes, gabinetes do utente e atividades de prevenção) e nos hospitais, sejam especializados e ou gerais (no acompanhamento e suporte psicossocial às famílias e doentes e a preparação de altas e a continuidade de cuidados no domicilio, entre outras), assim como nos centro de tratamento e reabilitação da toxicodependência.

Também desenvolve atividades na área da justiça ${ }^{21}$ na reinserção social de reclusos e ou de menores com pena, no acompanhamento e no estabelecendo de planos de integração social nessas áreas. Nesta área os assistentes sociais denominam-se técnicos de reeducação e ou de reinserção social. Na área do emprego e formação no acompanhamento de cursos de formação para públicos vulneráreis. Noutras áreas setoriais como a educação ${ }^{22}$ e a habitação a sua ação é menos expressiva. Nestas as assistentes sociais inserem-se nos departamentos de ação social e ou sociocultural e de saúde e ou de habitação em autarquias. Os assistentes nesta área desenvolvem projetos comunitários e outros de promoção do bem-estar da população.

Inserem-se igualmente em organizações não lucrativas as denominadas IPSS - Instituições sem Fins Lucrativos ${ }^{23}$ que podem ter a forma organizativa, por exemplo

\footnotetext{
${ }^{21} \mathrm{Na}$ área da justiça os licenciados em Serviço Social são considerados técnicos de reinserção e ou de reeducação.

${ }^{22}$ As autarquias são responsáveis pelo acompanhamento educacional das escolas do pré-escolar e $1^{\circ}$ ciclo.

${ }^{23}$ Estas segundo a lei 4/2007 prosseguem fins de segurança social, são tuteladas pelo estado, assim como financiadas e têm autonomia administrativa própria. Prestam serviços essencialmente na área das crianças, com creches e jardim infantil, mas também lares de acolhimentos; na área dos idosos com lares tradicionais, centros de dia e apoios domiciliários, contudo tem pouca expressão na intervenção na área da toxicodependência, HIV, sida, violência doméstica entre outros problemas emergentes na nossa sociedade.
} 
de Santas Casas da Misericórdia e ou de centros comunitários e de associações. Podem igualmente exercer a profíssão em empresas na área dos serviços sociais de apoio aos funcionários e em seguradoras, contudo o seu número é reduzido. Em Portugal não existe profissão liberal em Serviço Social, contudo nestes últimos anos têm surgido empresas associadas tanto a cuidados aos idosos, lares e suportes domiciliários, como seguradoras e empresas de trabalho temporário. Estas recrutam assistentes sociais para exercerem atividade no setor público, como é, por exemplo, o caso das comissões de proteção de menores.

Independentemente do campo de atuação os assistentes sociais desenvolvem a sua ação junto de grupos vulneráveis à pobreza e exclusão consubstanciada em desenvolvimento de programas e projetos de intervenção, que promovem a capacitação e o empowerment social e pessoal. As suas funções remetem para a concepção, planeamento e desenvolvimento das ações assim como avaliação, mas também podem ser técnicos de ação direta das políticas sociais existentes. Igualmente podem participar na elaboração de medidas de políticas ainda que de forma implícita.

Na atualidade o Serviço Social, ao nível educativo e formativo e de reconhecimento da profissão vê-se confrontado com a mudança de paradigma nestas duas dimensões. A reformulação do sistema de ensino, de acordo com as normas de Bolonha, centrado na ideia de formação ao longo da vida, alterou a estrutura curricular e a filosofia de base dos cursos. A universidade vê-se agora obrigada a desenvolver a formação centrada numa ideia de "fileira" de diplomas, onde a formação de base passou a ser de três anos, os mestrados de dois anos e os doutoramentos de três anos. Esta nova filosofia requer novas metodologias de aprendizagem que parece ainda não terem sido refletidas nem implementadas com claro prejuízo para a profissão, a qual passou, agora, para a ideia de mero executor de políticas e não para um profissional com capacidade de 
refletir sobre as mesmas e sobre as implicações, dessas orientações, para a vida das populações com as quais trabalha. Aos profissionais é requerida capacidade de ação no sentido de resolução dos problemas sociais rapidamente e com menos recursos.

\section{PARA CONCLUIR}

De uma concepção de profissão de "ajuda", de caridade e de assistência o Serviço Social passou a ser entendido como uma profissão da mudança social. Essa mudança é operada numa articulação entre o indivíduo e a sociedade e não separadamente, na concretização de direitos de cidadania onde estão implícitas a noção de justiça social, equidade social e autodeterminação dos indivíduos e grupos. O Serviço Social remete para a melhoria da qualidade de vida dos indivíduos no sentido da concretização das suas expectativas e interesses, efetivando os princípios e valores anteriormente referidos, para o desenvolvimento de capital social.

Os problemas, quer de adaptação e ou de readaptação, de exclusão e de integração de indivíduos, grupos e comunidades em interação com a sociedade, cultura, valores, conhecimento e níveis de informação, constituem o objeto do Serviço Social. O seu objetivo é melhorar a vida dos indivíduos. Para o concretizar é necessário ter presente as especificidades e singularidades da sociedade, tornando-a mais justa e equitativa no sentido de construção de espaços onde o ser humano possa viver partilhando as diferenças e aprendendo a respeitá-las.

O Serviço Social utiliza o seu conhecimento para interpretar, analisar e determinar os fatores de risco e proteção, potenciando com as pessoas formas de ação e de intervenção que promovam a sua autonomia, entendida como participação e escolha, mesmo que as políticas nas quais está incluída a intervenção não incluam essa dimensão. Atualmente o Serviço Social é concetualizado como uma ciência prática (cf. 
FALEIROS, 1997), orientada para o questionamento do conhecimento científico de modo a que ele possa ser utilizado para a promoção de uma sociedade mais justa. Os problemas são complexos e a ação exige uma abordagem multidisciplinar dos problemas, assim como um trabalho multiprofissional.

Numa sociedade global e tecnicista o Serviço Social tende a ser cada vez mais racional, controlado por legislação e protocolos de atuação enfatizando a técnica como "quase" um fim e não como meio da sua ação. A "intervenção tecnológica" coloca muitos desafios ao Serviço Social, designadamente no exercício de certos princípios e valores implícitos na sua génese: por um lado, a partilha, a solidariedade e o cuidado do outro e, por outro lado, a liberdade, a igualdade e os direitos fundamentais implícitos nos direitos humanos. Estas abordagens requerem uma nova abordagem ao ser humano, uma perspectiva holista, que integre padrões teóricos e padrões deontológicos da identidade da profissão e uma cultura de associação teoria e prática.

\begin{abstract}
This essay examines the development of training and the profession of Social Work in Portugal from particular times and spaces. To perform this survey we focused on literature search of reference texts, published in recent years and also in the author's experience as a teacher in higher Education System in Portugal. Situate the emergence, construction and recent developments in two dimensions in the study, training and profession and reflect on the challenges today. We believe that either the training or the profession of Social Work have substantial changes since its beginning to the present, arising from social changes associated with the changes of political system, the evolution of knowledge of Social Sciences and Humanities and the complexity of social problems constituting while route is crossed between assistance and rights.
\end{abstract}

KEYWORDS: Social Work, Education, Profession, Assistance, Rights 


\section{REFERÊNCIAS BIBLIOGRÁFICAS}

ANDRADE, M. Campo de Intervenção do Serviço Social, Autonomias e Heteronomias do Agir. Revista Intervenção Social, nº 23/24. Lisboa, ISSSL, Departamento Editorial. 2001.

FALEIROS, V. P. Estratégias em Serviço Social. São Paulo: Cortez Editora. 1997.

FERNANDES, A.; DIAS, H.; FERREIRA, M. de L.; CABRITA, T. O surgimento do

Serviço Social nas Misericórdias Portuguesas. Revista Intervenção Social. $\mathrm{n}^{0}$, Lisboa: ISSSL, Departamento Editorial. 1993.

FOOK, J. Social Work, Critical Theory and Practice. Reprinted, London: Sage Publications. 2003.

GARNIER, J. F. Assistante Social: pour la Redefinition d'un Métier. Paris: L'Harmattan. 1999.

MARQUES, E.; MOURO, H. Portugal, In: CAMPANINI, A.; FROST, E. (Ed.), European Social Work, Commonalities and Differences, Roma: Caracci Editori. 2004. pp. 182-188.

MARTINS, A.M. de C. A Escola da Ciência Social de Le Play na Construção do Conhecimento do Serviço Social Português. Revista Intervenção Social, $n^{0}$ 7, Lisboa, ISSSL. 1993.

MARTINS, A.M. de C. Investigação em Serviço Social: perspectivas atuais. In: HENRÍQUEZ, A.; FARINHA, M.A. (Orgs.). Serviço Social: Unidade na Diversidade Encontro com a Identidade Profissional. Lisboa: APSS. 2003.

NEgreIRos, A.G. As Representações Sociais da Profissão de Serviço Social. Lisboa: ISSSL. Departamento Editorial. 1995. 